\title{
Reintervention rate of arachnolysis versus shunting for nonforaminal syringomyelia
}

\author{
Gonzague Guillaumet, MD, ${ }^{1}$ Nozar Aghakhani, MD, PhD, ${ }^{1,2}$ Silvia Morar, MD, ${ }^{1}$ Razvan Copaciu, MD,1 \\ Fabrice Parker, MD, ${ }^{1,2}$ and Steven Knafo, MD, PhD ${ }^{1,2}$
}

\begin{abstract}
1'Department of Neurosurgery, French National Center for Chiari and Syringomyelia (C-MAVEM), Bicêtre Hospital, AP-HP, Paris-Saclay University, Paris; and ${ }^{2}$ Medical School, Paris-Saclay University, Le Kremlin-Bicêtre, Paris, France
\end{abstract}

\begin{abstract}
OBJECTIVE Surgical treatment for nonforaminal syringomyelia related to spinal arachnoiditis is still controversial. The authors sought to assess respective outcomes and rates of reintervention for shunting and spinal cord untethering (arachnolysis) in spinal arachnoiditis with syringomyelia.

METHODS This retrospective cohort study was conducted at a single reference center for syringomyelia. Patients undergoing arachnolysis and/or shunting interventions for nonforaminal syringomyelia were screened.

RESULTS The study included 75 patients undergoing 130 interventions. Arachnolysis without shunting was performed in 48 patients, while 27 patients underwent shunting. The mean follow-up between the first surgery and the last outpatient visit was 65.0 months (range 12-379 months, median 53 months). At the last follow-up, the modified McCormick score was improved or stabilized in $83.4 \%$ of patients after arachnolysis versus $66.7 \%$ after shunting. Thirty-one (41.3\%) patients underwent reintervention during follow-up, with a mean delay of 33.2 months. The rate of reintervention was $29.2 \%$ in the arachnolysis group versus $63.0 \%$ in the shunting group (chi-square $=8.1, p=0.007$ ). However, this difference was largely driven by the extension of the arachnoiditis: in patients with focal arachnoiditis ( $\leq 2$ spinal segments), the reintervention rate was $21.6 \%$ for arachnolysis versus $57.1 \%$ for shunting; in patients with extensive arachnoiditis, it was $54.5 \%$ versus $65.0 \%$, respectively. Survival analysis assessing the time to the first reintervention demonstrated a better outcome in both the arachnolysis $(p=0.03)$ and the focal arachnoiditis $(p=0.04)$ groups.
\end{abstract}

CONCLUSIONS Arachnolysis led to fewer reinterventions than shunting in patients with nonforaminal syringomyelia. There was a high risk of reintervention for patients with extensive arachnopathies, irrespective of the surgical technique. https://thejns.org/doi/abs/10.3171/2020.8.SPINE20928

KEYWORDS syringomyelia; arachnoiditis; arachnolysis; shunt; spinal cord; surgery; surgical technique

$\mathrm{S}$ YRINGOMYELIA is a condition characterized by a progressive cystic cavity within the spinal cord that results from a dysfunction of CSF circulation., ${ }^{1,2}$ The obstruction can take place either at the level of the foramen magnum (e.g., a Chiari malformation) or within spinal subarachnoid spaces (e.g., arachnoiditis, whether posttraumatic or not). Therefore, every time it is feasible, treatment of syringomyelia should aim to restore CSF circulation.

There is still no clear consensus about the best treatment option for syringomyelia related to spinal arachnoiditis. ${ }^{3,4}$ Several reported studies have demonstrated that spinal arachnolysis, with or without duraplasty, is beneficial for posttraumatic arachnoiditis..$^{5-7}$ However, an important issue that was not specifically addressed in previous studies is the rate of reintervention in relation to the extension of the arachnoiditis and the type of surgery. Indeed, many patients with arachnoiditis undergo multiple interventions as their neurological status deteriorates, leading to more hospital stays and iatrogenic comorbidities.

In this study, we aimed to investigate the association of arachnolysis with shunting procedures for nonforaminal syringomyelia, with a focus on reintervention rate and arachnoiditis extension.

\section{Methods \\ Patients}

We screened all patients undergoing surgery for either "spinal cord untethering" or "spinal shunting" at the neurosurgery department of Bicêtre Hospital (AP-HP, Paris-Saclay University, C-MAVEM national reference center for syringomyelia) between 2004 and 2018. Ethical approval was obtained from the scientific advisory committee of the C-MAVEM reference center. According to 
our hospital policy, patients gave consent for inclusion in future observational studies before every surgery. Among the 109 patients whose data were retrieved (51 spinal cord untethering surgeries and 58 shunting procedures), we only included patients presenting with syringomyelia related to nonforaminal arachnoiditis (i.e., excluding syringomyelia associated with a Chiari malformation). In the present study, "arachnoiditis" refers to the pathologic inflammatory process tacking place in the subarachnoid spaces and causing obstruction of CSF circulation, ultimately resulting in syringomyelia (i.e., formation of a progressive intramedullary cystic cavity).

For every eligible patient, clinical and radiological features were retrospectively extracted from medical records. We only included patients for whom pre- and postoperative clinical examination and spinal cord MRI, including millimeter-scale T2 and CSF flow sequences, along with operative reports were available. Clinical and MRI features were independently assessed by two neurosurgeons to minimize evaluation biases. Four neurosurgeons (F.P., N.A., S.M., and S.K.) were involved in the surgeries reported in the present study.

Clinical evaluation included assessment of the ability to walk, neuropathic pain, motor and sensory deficits, sphincter dysfunction, and the modified McCormick Scale score. ${ }^{8}$ MRI evaluation assessed the extension of the arachnoiditis and syringomyelia, subarachnoid CSF obstruction, and flow within the syrinx. The dates of the causal event (when appropriate), surgery, and last followup were noted.

Patients were grouped according to the etiology and extent of the arachnoiditis: it was considered focal if the extension was $\leq 2$ spinal segments or extensive if it was $\geq$ 3 segments. ${ }^{9}$

\section{Surgery}

Surgery was only proposed to patients with a progressive clinical myelopathy (i.e., sensory, motor, or sphincter deficits). Neuropathic pain, if isolated, was not a sufficient cause to proceed to surgery, since it rarely improves afterward.$^{10}$ Similarly, reintervention was only proposed if motor deterioration was observed and extension of the syrinx, typically cranially, was noted.

For arachnolysis procedures, a laminectomy was performed in order to expose, whenever possible, the spinal cord above and below the CSF obstruction. The dura was opened on the midline and the spinal cord was untethered from the arachnoid scarring using sharp dissection. Dissection was followed until communication was achieved between the cranial and caudal subarachnoid spaces and the dentate ligaments were opened laterally. Arachnolysis was deemed successful when CSF flow and spinal cord pulsatility were restored. When these criteria were not met, the surgeon combined a shunting procedure within the same surgery and/or a duraplasty using synthetic material (Neuro-Patch, B. Braun).

Shunting procedures included either syringo-peritoneal, syringo-subarachnoid, subarachnoid-subarachnoid, or subarachnoid-peritoneal shunts. The choice of shunt type was at the discretion of the surgeon. As a general rule, syringo-peritoneal shunts were used when the syrinx was wide and the cranial and caudal ends of the arachnoiditis could not be exposed, whereas subarachnoid shunts were preferred when the arachnoiditis was focal but untethering of the spinal cord was not adequate. ${ }^{11}$ Small lumboperitoneal catheters (inner diameter $1.5 \mathrm{~mm}$; Medtronic) without mechanical connectors or adjustable hardware were used; a midline myelotomy was performed, and the catheter was attached to the pia and/or dura to avoid subsequent migration.

\section{Data Analysis}

A custom electronic case report form was completed for each patient and data were analyzed independently by two neurosurgeons using SPSS software (version 23; IBM Corp.). To avoid evaluation biases due to the retrospective nature of this cohort study, we emphasized the time to reintervention rather than clinical outcome or time to neurological recurrence. For patients on whom surgery was first conducted in another center $(n=2)$, we considered the delay between the first surgery and the first reintervention performed in our department. Comparisons of proportions between groups were performed with chi-square tests. Survival analysis was performed using Kaplan-Meier curves and the log-rank test for univariate analysis and the Cox model for multivariate analysis.

\section{Results}

\section{Baseline Clinical Features}

Of 109 patients screened, 75 patients matched the inclusion criteria and were included in the final analysis (exclusion for syringomyelia due to Chiari malformation, $\mathrm{n}=$ 16; for incomplete medical records, $\mathrm{n}=18$ ). The mean age at the first surgery was 45.8 years (range 18-74 years) and $72 \%$ were men. In cases in which the date of the causal event of the arachnoiditis could be identified (49/75 patients), the mean delay between this event and the first surgery was 129.1 months (range 3-660 months). Posttraumatic arachnoiditis was the most common etiology (34/75, $45 \%)$, followed by idiopathic $(18 / 75,24 \%)$ and iatrogenic (postsurgical; $12 / 75,16 \%)$, postinfectious $(8 / 75,11 \%)$, and posthemorrhagic $(3 / 75,4 \%)$ arachnopathies. All patients presented with sensory deficits (dysesthesia or hypesthesia) and most with neuropathic pain (70/75, 93\%). Most patients had motor deficits $(69 / 75,92 \%)$ and only $20 / 75$ patients $(27 \%)$ were able to walk without assistance. More than half of the patients $(48 / 75,64 \%)$ had vesical dysfunction. Regarding the preoperative modified McCormick scores among patients, $16 \%$ were functionally independent (grades 1-2), 36\% had some limitation of function (grade 3), and 48\% were dependent (grades 4-5) (Table 1).

\section{Baseline Radiological Findings}

Preoperative MRI showed focal arachnoiditis $(\leq 2 \mathrm{spi}-$ nal segments) in 44/75 (59\%) patients and extensive ( $\geq 3$ spinal segments) arachnoiditis in 31/75 patients (Table 2). The mean length of the arachnoiditis was 3.6 spinal segments (range 1-20), and it was localized in the dorsal region in most patients $(48 / 75,64 \%)$. As expected, the mean extension of the secondary syringomyelia was larger than that of the arachnoiditis itself (mean 11.7 spinal segments, 
TABLE 1. Baseline clinical features

\begin{tabular}{|c|c|}
\hline & Value \\
\hline \multicolumn{2}{|l|}{ Patient } \\
\hline Age at first surgery, yrs & $45.8 \pm 13.4(18-74)$ \\
\hline Sex ratio: male/female & $54 / 21(72 \% / 28 \%)$ \\
\hline \multicolumn{2}{|l|}{ Etiology } \\
\hline Idiopathic & $18(24.0 \%)$ \\
\hline Posttraumatic & $34(45.3 \%)$ \\
\hline Postoperative & $12(16.0 \%)$ \\
\hline Postinfectious & $8(10.7 \%)$ \\
\hline Posthemorrhagic & $3(4.0 \%)$ \\
\hline \multicolumn{2}{|l|}{ Clinical features } \\
\hline Time from diagnosis to surgery, mos & $30.9(1-180)$ \\
\hline Time from etiology to diagnosis, mos & $129.1(3-660)$ \\
\hline Neuropathic pain & $70(93.3 \%)$ \\
\hline \multicolumn{2}{|l|}{ Ability to walk } \\
\hline Without assistance & $20(26.7 \%)$ \\
\hline With assistance & $25(33.3 \%)$ \\
\hline Unable & $30(40.0 \%)$ \\
\hline \multicolumn{2}{|l|}{ Motor deficit } \\
\hline Upper limbs & $9(12.0 \%)$ \\
\hline Lower limbs & $43(57.3 \%)$ \\
\hline Upper \& lower limbs & $17(22.7 \%)$ \\
\hline \multicolumn{2}{|l|}{ Sensory deficit } \\
\hline Upper limbs & $7(9.3 \%)$ \\
\hline Lower limbs & $36(48.0 \%)$ \\
\hline Upper \& lower limbs & $32(42.7 \%)$ \\
\hline \multicolumn{2}{|l|}{ Sphincter dysfunction } \\
\hline Vesical & $48(64.0 \%)$ \\
\hline Anal & $7(9.3 \%)$ \\
\hline \multicolumn{2}{|l|}{ Preop modified McCormick grade } \\
\hline 1 & 0 \\
\hline 2 & $12(16 \%)$ \\
\hline 3 & $27(36 \%)$ \\
\hline 4 & $14(18.7 \%)$ \\
\hline 5 & $22(29.3 \%)$ \\
\hline
\end{tabular}

Values are presented as number (\%) of patients, mean \pm SD (range), or mean (range).

range 1-21) and more frequently encompassed several spinal regions. CSF flow within the syrinx was observed in more than one-third of cases $(27 / 75,36 \%)$.

\section{Surgical Procedures}

Untethering of the spinal cord through arachnolysis alone was performed in 48/75 (64\%) patients, in those cases in which it sufficed to restore CSF flow in the subarachnoid spaces. There were 27 (36\%) shunting procedures. Shunting only (without associated arachnolysis) was performed in 14 patients: in most cases this was a syringoperitoneal shunt (10/14) to address a large syringomyelia (> 10 spinal segments in 11/14 patients) secondary to extensive arachnoiditis (12/14 patients). When shunting was
TABLE 2. Baseline radiological findings

\begin{tabular}{|c|c|}
\hline & Value \\
\hline \multicolumn{2}{|l|}{ Arachnopathy } \\
\hline Focal ( $\leq 2$ segments) & $44(58.7 \%)$ \\
\hline Extensive ( $\geq 3$ segments) & $31(41.3 \%)$ \\
\hline \multicolumn{2}{|l|}{ Spinal segments } \\
\hline C & 11 \\
\hline $\mathrm{CT}$ & 3 \\
\hline CTL & 2 \\
\hline $\mathrm{L}$ & 2 \\
\hline $\mathrm{T}$ & 48 \\
\hline $\mathrm{TL}$ & 9 \\
\hline No. of spinal segments & $3.6 \pm 3.8(1-20)$ \\
\hline \multicolumn{2}{|l|}{ Syringomyelia } \\
\hline \multicolumn{2}{|l|}{ Spinal segments } \\
\hline C & 4 \\
\hline CT & 29 \\
\hline CTL & 16 \\
\hline $\mathrm{T}$ & 20 \\
\hline $\mathrm{TL}$ & 6 \\
\hline No. of spinal segments & $11.7 \pm 36.7(1-21)$ \\
\hline Intracavity CSF flow & $27(36.0 \%)$ \\
\hline
\end{tabular}

$\mathrm{C}=$ cervical; $\mathrm{CT}=$ cervico-thoracic; $\mathrm{CTL}=$ cervico-thoraco-lumbar; $\mathrm{L}=$ lumbar; $\mathrm{T}=$ thoracic; $\mathrm{TL}=$ thoraco-lumbar.

Values are presented as number or number (\%) of patients or mean \pm SD (range).

associated with partial arachnolysis (13/75), the shunt type was either syringo-peritoneal (4/13), syringo-subarachnoid (4/13), subarachnoid-peritoneal (2/13), or subarachnoidsubarachnoid (3/13), depending on the operative findings (in particular, whether the cranial and caudal extremities of the arachnoiditis could be exposed). When a syringoperitoneal shunt was inserted, the myelotomy was preferentially localized at the dorso-lumbar junction when the syringomyelia was holocord (10/14) (Table 3; Fig. 1). In the initial postoperative period ( $<45$ days), there were 4 complications: 1 CSF leak, 2 hematomas, and 1 infection (all but one hematoma occurred after arachnolysis procedures).

\section{Outcome and Reintervention}

The mean follow-up between the first surgery and the last outpatient visit was 65.0 months (median 53 months, range 12-379 months). Overall, comparison of the preoperative modified McCormick score with the last follow-up score showed an improvement of 2 grades for 3/75 (4\%) patients and 1 grade for 14/75 (19\%) patients, stability in 43/75 (57\%) patients, and deterioration of 1 grade for $15 / 75(20 \%)$ patients. The last available MRI showed a decreased extension of the syringomyelia in 32/75 (43\%) patients, stability in 29/75 (39\%), and deterioration in $7 / 75$ (9\%) cases (Table 4).

At the last follow-up, among patients who initially underwent arachnolysis, 27/48 (56\%) were clinically stable according to the modified McCormick Scale score, where- 
TABLE 3. Surgical procedures

\begin{tabular}{lc}
\hline & Value \\
\hline Arachnolysis & $48(64.0 \%)$ \\
\hline Shunting & $27(36.0 \%)$ \\
\hline Shunting only & 14 \\
\hline Shunting w/ arachnolysis & 13 \\
\hline Shunt type & 14 \\
\hline Syringo-peritoneal & 6 \\
\hline Syringo-subarachnoid & 4 \\
\hline Subarachnoid-peritoneal & 3 \\
\hline Subarachnoid-subarachnoid & 7 \\
\hline Shunt localization & 9 \\
\hline C5-T3 & 11 \\
\hline T4-T8 & $21(28.0 \%)$ \\
\hline T10-L1
\end{tabular}

Values are presented as number or number (\%) of patients.

as 13/48 (27\%) had improved and 8/48 (16\%) had deteriorated. After initial shunting, a similar number of patients had stabilized (16/27, 59\%), but fewer had improved (2/27, $7 \%$ ) and more had deteriorated $(9 / 27,33 \%)$. This difference was mostly explained by the better clinical results of arachnolysis for focal arachnopathies (83\% of patients stabilized or improved, compared to $57 \%$ with shunting). The last available MR images obtained in patients who initially had arachnolysis showed a decrease in syrinx extension in $27 / 48(56 \%)$, stability in $17 / 48(35 \%)$, and progression in 4/48 (8\%) patients. Among patients who first underwent shunting, syrinx extension was decreased in $6 / 27(22 \%)$, stable in 18/27 (67\%), and progressive in 3/27 (11\%) patients. Again, the best results were obtained when arachnolysis was performed for focal arachnoiditis (89\% control rate vs $71 \%$ for shunting) (Table 5).
Among the 75 patients included, 31 (41\%) underwent reintervention with a median delay to the first reintervention of 20.5 months (range $0-168$ months [Q1 $=6.8, \mathrm{Q} 3=$ 49]). In most cases, this reintervention was either a shunt revision $(13 / 75,17 \%)$ or the addition of a new shunt in a patient who had arachnolysis as a first-line procedure (11/75, $15 \%$ ). Mechanical failures (disconnection, obstruction, or migration of the catheter) could be identified in 7/13 (54\%) shunt revisions. Overall, 130 surgeries were performed in 75 patients. Even though the majority of patients (44/75, $59 \%$ ) had only one surgery, a significant number of patients experienced multiple interventions: 16/75 (21\%) patients had three or more surgeries.

The rate of reintervention varied widely according to not only the type of the first surgery but also the extent of the arachnoiditis (Table 5). Overall, the rate of reintervention was higher in the shunting group than in the arachnolysis group $(63.0 \%$ vs $29.2 \%$, chi-square $=8.1, \mathrm{p}=0.007)$. Reintervention rates were comparable whether or not arachnolysis was performed in conjunction with shunting during the initial surgery (61.6\% vs $64.3 \%$, respectively). In patients who underwent shunting with arachnolysis, all revision surgeries were shunt related (addition or revision). Revision surgeries were also more frequent in patients with extensive compared to focal arachnopathies (61.3\% vs $27.3 \%$, chi-square $=8.7, \mathrm{p}=0.004$ ). More specifically, while it seems that arachnolysis led to fewer reinterventions than shunting in patients with focal arachnoiditis ( $21.6 \%$ vs $57.1 \%$ ), the reintervention rate was similar for both arachnolysis and shunting in patients with extensive arachnoiditis (54.5\% vs $65.0 \%$ ).

Survival analysis comparing the time to first reintervention between patients who underwent arachnolysis and patients treated with shunting demonstrated a better outcome for arachnolysis (log-rank, chi-square $=4.8, \mathrm{p}=$ 0.029; Fig. 2). However, a similar difference in progression-free survival was observed when focal and extensive arachnoiditis were compared (log-rank, chi-square $=$
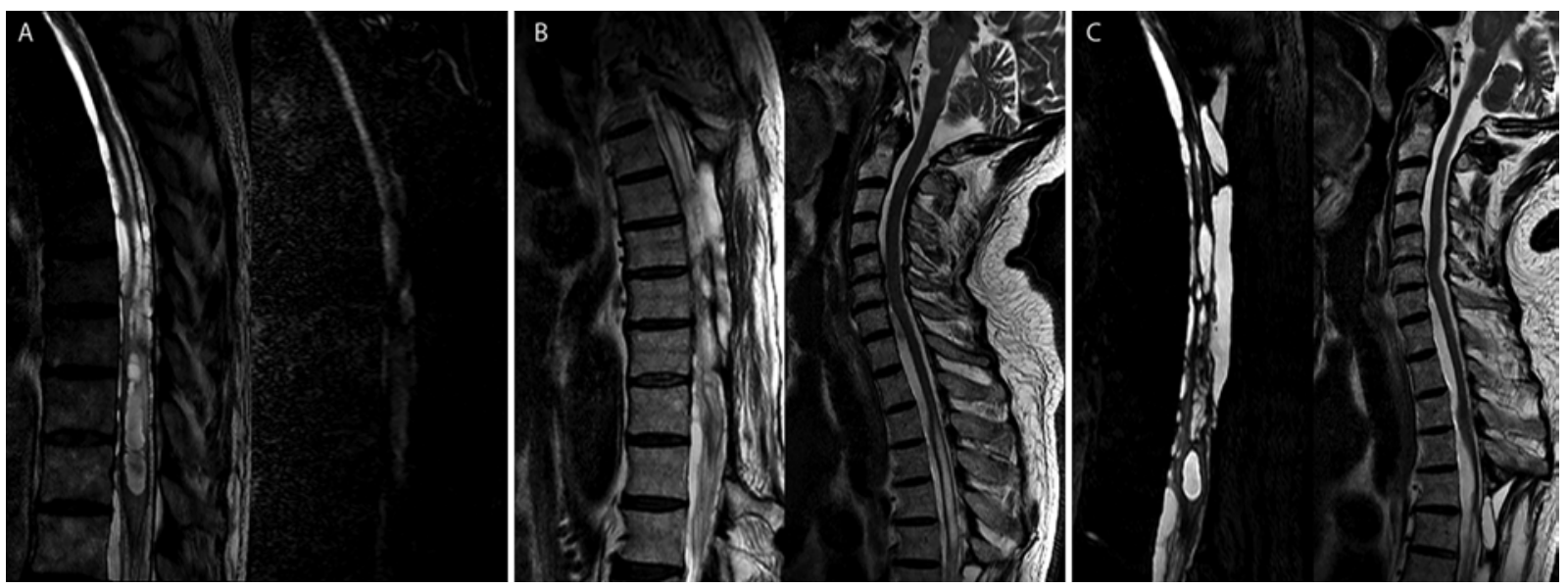

FIG. 1. Postinfectious arachnoiditis: failure of arachnolysis and secondary shunting. MRI studies from an illustrative case of a 64 -year-old patient who had meningitis for 11 years before presenting with progressive gait disability and neuropathic pain. A: Initial MRI revealed an extensive arachnoiditis from T8 to T11 with syringomyelia and CSF obstruction. B: The patient underwent arachnolysis without shunting. However, the syrinx progressed cranially, and syringo-peritoneal shunting was performed 13 months later. C: Eventually, the syrinx decreased, and patient was clinically stable 6 years postoperatively. 
TABLE 4. Overall outcome and reintervention

\begin{tabular}{|c|c|}
\hline & Value \\
\hline Follow-up duration, mos & $65 \pm 60.9(12-379)$ \\
\hline \multicolumn{2}{|l|}{ Last follow-up } \\
\hline \multicolumn{2}{|l|}{ Postop modified McCormick grade } \\
\hline 1 & $5(6.7 \%)$ \\
\hline 2 & $10(13.3 \%)$ \\
\hline 3 & $17(22.7 \%)$ \\
\hline 4 & $15(20.0 \%)$ \\
\hline 5 & $28(37.3 \%)$ \\
\hline \multicolumn{2}{|l|}{ Syrinx } \\
\hline Improved & $32(42.7 \%)$ \\
\hline Stable & $29(38.7 \%)$ \\
\hline Deteriorated & $7(9.3 \%)$ \\
\hline \multicolumn{2}{|l|}{ Reintervention } \\
\hline Yes & $31(41.3 \%)$ \\
\hline Time to first reintervention, mos & $33.2 \pm 40.4(0-168)$ \\
\hline \multicolumn{2}{|l|}{ Type } \\
\hline Arachnolysis & $7(9.3 \%)$ \\
\hline New shunt & $11(14.7 \%)$ \\
\hline Shunt revision & $13(17.3 \%)$ \\
\hline \multicolumn{2}{|l|}{ Total no. of interventions } \\
\hline 1 & 44 \\
\hline 2 & 15 \\
\hline 3 & 11 \\
\hline$\geq 4$ & 5 \\
\hline
\end{tabular}

Values are presented as number or number (\%) of patients or mean \pm SD (range).

$4.5, \mathrm{p}=0.035)$. This result was expected given that most patients with focal arachnoiditis underwent arachnolysis $(37 / 44,84 \%)$, whereas most extensive arachnopathies were treated with shunting $(20 / 31,65 \%)$. According to the multivariate analysis, neither the extension of the arachnoiditis (HR 1.1, 95\% CI 0.99-1.16, p = 0.10) nor the type of surgery (HR $0.6,95 \%$ CI $0.25-1.22, p=0.14$ ) could independently explain the difference in terms of the delay to reintervention.

\section{Discussion}

In this retrospective cohort of patients operated on for nonforaminal syringomyelia, we showed that arachnolysis was associated with better clinical results and fewer reinterventions than shunting procedures. However, this effect was largely driven by the fact that patients with syringomyelia secondary to focal arachnoiditis ( $\leq 2$ spinal segments) were more likely to benefit from arachnolysis than patients with extensive arachnoiditis. For the latter cases, both arachnolysis and shunting required reintervention rates $>50 \%$ in order to obtain clinical and radiological control of the disease.

We conclude that arachnolysis should be proposed as a first-line treatment to patients with nonforaminal syringomyelia in every case in which the spinal arachnoiditis
TABLE 5. Outcomes according to type of first surgery and arachnopathy extension

\begin{tabular}{|c|c|c|c|}
\hline & \multicolumn{2}{|c|}{ Arachnopathy } & \multirow[b]{2}{*}{ Total } \\
\hline & Focal & Extensive & \\
\hline \multicolumn{4}{|c|}{$\begin{array}{l}\text { McCormick score, } \\
\text { improved or stabi- } \\
\text { lized }\end{array}$} \\
\hline Arachnolysis & $31 / 37(83.4 \%)$ & 9/11 (81.8\%) & $40 / 48(83.3 \%)$ \\
\hline Shunting & $4 / 7(57.1 \%)$ & $14 / 20(70.0 \%)$ & $18 / 27(66.7 \%)$ \\
\hline Total & $35 / 44(79.5 \%)$ & $23 / 31(74.2 \%)$ & $58 / 75(77.3 \%)$ \\
\hline \multicolumn{4}{|c|}{$\begin{array}{l}\text { Syrinx extension, im- } \\
\text { proved or stabilized }\end{array}$} \\
\hline Arachnolysis & $33 / 37(89.2 \%)$ & $11 / 11(100 \%)$ & $44 / 48(91.7 \%)$ \\
\hline Shunting & $5 / 7(71.4 \%)$ & $19 / 20(95.0 \%)$ & $24 / 27(88.9 \%)$ \\
\hline Total & $38 / 44(86.4 \%)$ & $30 / 31(96.8 \%)$ & $68 / 75(90.7 \%)$ \\
\hline \multicolumn{4}{|c|}{ Reintervention rate } \\
\hline Arachnolysis & $8 / 37(21.6 \%)$ & $6 / 11(54.5 \%)$ & $14 / 48(29.2 \%)$ \\
\hline Shunting & $4 / 7(57.1 \%)$ & $13 / 20(65.0 \%)$ & $17 / 27(45.9 \%)$ \\
\hline Total & $12 / 44(27.3 \%)$ & $19 / 31(61.3 \%)$ & $31 / 75(41.3 \%)$ \\
\hline
\end{tabular}

is focal. In cases of extensive arachnoiditis, both treatment options lead to a high rate of reintervention and patients should be informed of this risk. In such cases, several options are possible: extensive arachnolysis, with or without adjunction of a shunt; shunting only; and, of course, nonsurgical management. Since, as evidenced by the present study, surgery for extensive arachnoiditis carries a significant risk of reoperation, we try to stick with medical management as long as possible and only opt for surgery if progressive neurological deterioration threatens essential functions (e.g., the motor status of the upper limbs in a paraplegic patient). If the patient requires surgery, we recommend arachnolysis with the adjunction of subarachnoid-subarachnoid shunting over the craniocaudal extension of the syrinx. When arachnolysis is not feasible, because the arachnoiditis is too extensive or circumferential, and if syringomyelia is present, we opt for a syringo-peritoneal shunting inserted at the lower extremity of the syrinx.

This conclusion is of course subject to several limitations of our study. In particular, the retrospective nature of data collection and the large range of follow-up can lead to evaluation biases. Moreover, the patient population is heterogenous regarding the etiology of the arachnoiditis. However, these limitations are inherent to the rarity of this condition: several years are required before collecting a significant number of cases within a single center, and multicenter studies would imply even larger heterogeneity in patients and methods. Lastly, since only patients with progressive motor or sensory deficit underwent surgery, one cannot conclude from our study that surgery of arachnoiditis would fail to improve subjective symptoms such as neuropathic pain. However, given the high risk of neurological complication and reintervention, and the multifactorial etiology of pain in these patients, we do not believe it is reasonable to indicate surgery for patients without myelopathy. 

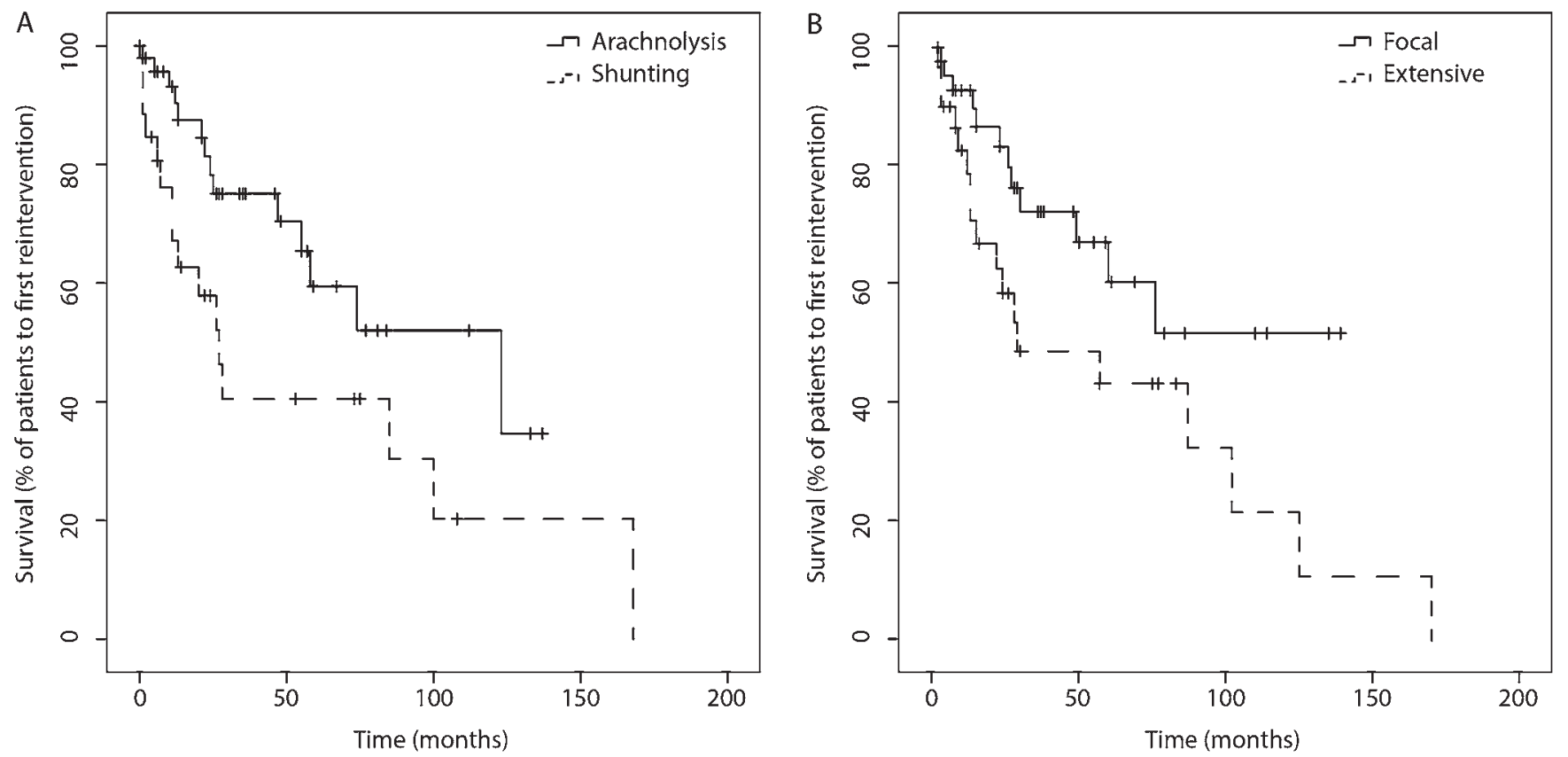

FIG. 2. Survival analysis according to first intervention and arachnoiditis extension. A: Time to first reintervention according to type of first surgery: arachnolysis versus shunting. B: Time to first reintervention according to arachnoiditis extension: focal $(\leq 2$ spinal segments) versus extensive ( $\geq 3$ spinal segments).

We decided to emphasize the reintervention rate rather than clinical examination as the main outcome measure of the study since clinical status in patients with syringomyelia is subject to a wide range of factors (neuropathic pain, neuro-urological complications, pressure ulcers, etc.). Even though this decision introduces a surgical bias, we believe it is more appropriate to evaluate the outcome specifically related to the surgical procedure, which was the topic of the present study.

Our results confirm previous results and in particular those published by Klekamp in his original paper. ${ }^{9}$ In his initial study, which reviewed 121 surgeries in 78 patients with a mean follow-up of 32 months, decompression (i.e., laminectomy, arachnolysis, followed either by duraplasty or by leaving the dura open) led to better outcomes than shunting in patients with focal arachnoiditis (17\% of neurological recurrence and $23 \%$ of syrinx expansion for grades I and II). However, decompression in patients with extensive arachnoiditis (grade III or IV) exposed patients to high rates of clinical $(83 \%)$ and radiological $(50 \%)$ recurrence, comparable to shunting procedures ( $97 \%$ clinical recurrence and $49 \%$ syrinx expansion, with no difference between focal and extensive arachnoiditis). As a consequence of these results, Klekamp mostly performed arachnolysis with duraplasty from 1997 onward. Subsequent reports of his personal cohort, both for posttraumatic ${ }^{12}$ and nontraumatic arachnoiditis,,$^{13}$ confirmed that arachnolysis provided satisfactory long-term clinical and radiological results in patients with focal but not with extensive arachnoiditis (rates of progression-free survival at 10 years, $78 \%$ vs $31 \%$, respectively ${ }^{13}$ ).

Our results are also in line with other studies that focused on syringomyelia due to posttraumatic arachnoiditis.
In 2010, in 34 patients with posttraumatic syringomyelia, our group showed that the rate of progression-free survival after 10 years was approximately $60 \%$ for those who underwent arachnolysis versus $20 \%$ for shunting procedures; the reintervention rate was 5\% (1/19) in the arachnolysis group versus $73 \%$ (11/15) in the shunting group. ${ }^{6}$ However, this study did not take into account the extension of the arachnoiditis nor the time to reintervention. In another retrospective cohort including only arachnolysis procedures, the rate of reintervention was $43 \%$ (17/40) patients with a mean follow-up of 64 months, with no precision regarding arachnoiditis extension. ${ }^{7}$ Lastly, a small but comparative case series including 27 patients with posttraumatic arachnoiditis found a recurrence rate of 10/16 (63\%) after shunting versus $3 / 11(27 \%)$ after duraplasty, with a mean follow-up of 18 years. ${ }^{5}$

As a consequence of these studies, a systematic review of the literature led a consensus panel to give a "weak recommendation" favoring spinal cord untethering and duraplasty over shunting as a first-line surgical treatment in posttraumatic syringomyelia..$^{0}$ Moreover, they delivered a "strong recommendation" for surgery in cases in which motor deterioration, but not sensory deficit or pain, occurs. ${ }^{10}$ However, the extension of the arachnoiditis was not taken into account, even though previous studies had demonstrated the importance of this factor for the long-term control of syringomyelia.

\section{Conclusions}

In the present study, arachnolysis was associated with better clinical and radiological results than shunting procedures. However, for arachnopathies extending $\geq 3$ spinal 
segments, both arachnolysis and shunting led to reintervention in more than half of the patients. Hence, for patients with extensive arachnopathies, surgery should only be considered if neurological deterioration poses crucial limitations, taking into account the current functional status of the patient and if significant improvement in quality of life is expected from the procedure.

\section{References}

1. Klekamp J. How should syringomyelia be defined and diagnosed? World Neurosurg. 2018;111:e729-e745.

2. Heiss JD, Patronas N, DeVroom HL, et al. Elucidating the pathophysiology of syringomyelia. J Neurosurg. 1999;91(4): 553-562.

3. Than KD, Mummaneni PV. Perspective: surgical options for adult syringomyelia. World Neurosurg. 2015;83(4):464-465.

4. Ghobrial GM, Dalyai RT, Maltenfort MG, et al. Arachnolysis or cerebrospinal fluid diversion for adult-onset syringomyelia? A systematic review of the literature. World Neurosurg. 2015;83(5):829-835.

5. Karam Y, Hitchon PW, Mhanna NE, et al. Post-traumatic syringomyelia: outcome predictors. Clin Neurol Neurosurg. 2014;124:44-50.

6. Aghakhani N, Baussart B, David P, et al. Surgical treatment of posttraumatic syringomyelia. Neurosurgery. 2010;66(6): $1120-1127$.

7. Ushewokunze SOS, Gan YC, Phillips K, et al. Surgical treatment of post-traumatic syringomyelia. Spinal Cord. 2010; 48(9):710-713.

8. Shrivastava RK, Epstein FJ, Perin NI, et al. Intramedullary spinal cord tumors in patients older than 50 years of age: management and outcome analysis. J Neurosurg Spine. 2005; 2(3):249-255.

9. Klekamp J, Batzdorf U, Samii M, Bothe HW. Treatment of syringomyelia associated with arachnoid scarring caused by arachnoiditis or trauma. J Neurosurg. 1997;86(2):233-240.
10. Bonfield CM, Levi AD, Arnold PM, Okonkwo DO. Surgical management of post-traumatic syringomyelia. Spine (Phila Pa 1976). 2010;35(21)(suppl):S245-S258.

11. Vaquero J, Martínez R, Salazar J, Santos H. Syringosubarachnoid shunt for treatment of syringomyelia. Acta Neurochir(Wien). 1987;84(3-4):105-109.

12. Klekamp J. Treatment of posttraumatic syringomyelia. J Neurosurg Spine. 2012;17(3):199-211.

13. Klekamp J. Treatment of syringomyelia related to nontraumatic arachnoid pathologies of the spinal canal. Neurosurgery. 2013;72(3):376-389.

\section{Disclosures}

The authors report no conflict of interest concerning the materials or methods used in this study or the findings specified in this paper.

\section{Author Contributions}

Conception and design: Knafo, Aghakhani, Parker. Acquisition of data: Guillaumet, Copaciu. Analysis and interpretation of data: Knafo, Guillaumet. Drafting the article: Knafo. Critically revising the article: Aghakhani, Morar, Parker. Reviewed submitted version of manuscript: Knafo, Guillaumet, Aghakhani, Morar, Parker. Approved the final version of the manuscript on behalf of all authors: Knafo. Statistical analysis: Knafo. Study supervision: Knafo.

\section{Correspondence}

Steven Knafo: Bicêtre Hospital, Le Kremlin-Bicêtre, Paris, France.steven.knafo@aphp.fr. 